\title{
Review
}

\section{Genomics of pear and other Rosaceae fruit trees}

\author{
Toshiya Yamamoto* and Shingo Terakami
}

NARO Institute of Fruit Tree Science, 2-1 Fujimoto, Tsukuba, Ibaraki 305-8605, Japan

The family Rosaceae includes many economically important fruit trees, such as pear, apple, peach, cherry, quince, apricot, plum, raspberry, and loquat. Over the past few years, whole-genome sequences have been released for Chinese pear, European pear, apple, peach, Japanese apricot, and strawberry. These sequences help us to conduct functional and comparative genomics studies and to develop new cultivars with desirable traits by marker-assisted selection in breeding programs. These genomics resources also allow identification of evolutionary relationships in Rosaceae, development of genome-wide SNP and SSR markers, and construction of reference genetic linkage maps, which are available through the Genome Database for the Rosaceae website. Here, we review the recent advances in genomics studies and their practical applications for Rosaceae fruit trees, particularly pear, apple, peach, and cherry.

Key Words: apple, co-linearity, genome sequence, peach, pear, reference map.

\section{Introduction}

The family Rosaceae consists of about 2500 species from 90 genera and includes diverse plants, which are primarily native to temperate regions (Hummer and Janick 2009). This family was traditionally classified into several subfamilies: Amygdaloideae, Maloideae, Rosoideae, Spiraeoideae, and others (Hummer and Janick 2009). In 2007, three subfamilies were suggested: Dryadoideae, Rosoideae and Amygdaloideae (Potter et al. 2007); the latter subfamily includes the former Amygdaloideae, Maloideae and Spiraeoideae. Many economically important crops producing edible fruits (e.g., apple, apricot, cherry, loquat, peach, pear, plum, quince, raspberry, and strawberry), nuts (e.g., almond), and ornamentals (e.g., rose) belong to the Rosaceae.

The most economically important members of the Rosaceae are apples (Malus $\times$ domestica Borkh.) and pears (Pyrus spp.), both of which belong to the subfamily Amygdaloideae, tribe Pyreae. Annual world fruit production of apples exceeds 80 million tons (FAOSTAT 2013), making them the third most important fruit (after citrus and banana). Pears are the second most important fruit species in Rosaceae, with world production of approximately 25.2 million tons (FAOSTAT 2013). Four important Pyrus species are commercially grown for edible fruit: Japanese pear ( $P$. pyrifolia Nakai), European pear (P. communis L.), and Chinese pears (P. bretschneideri Rehd. and P. ussuriensis Maxim.) (Bell et

Communicated by M. Omura

Received September 10, 2015. Accepted January 12, 2016.

*Corresponding author (e-mail: toshiya@affrc.go.jp) al. 1996). Loquat (Eriobotrya japonica (Thunb.) Lindl.) is also an important fruit tree that belongs to the tribe Pyreae along with pears and apples. Several Prunus ("stone fruit") species are also important fruit trees and include peaches and nectarines (P. persica (L.) Batsch), plums (P. domestica L., $P$. salicina Lindl.), apricots (P. armeniaca L., P. mume Siebold et Zucc.), and cherries (P. avium L., P. cerasus L.), which belong to the subfamily Amygdaloideae, tribe Amygdaleae. Annual world fruit production (in million tons) is as follows: peaches and nectarines, 21.6; plums, 11.5; apricots, 4.1; and cherries 2.3 (FAOSTAT 2013). In Japan, domestic fruit production (in thousand tons) is as follows: apples, 742; pears, 294; peaches, 125; apricots, 124; plums, 21; and cherries, 18 (FAOSTAT 2013).

Basic chromosome number $x=7,8,9,15$ or 17 was observed for Rosaceae members (Dirlewanger et al. 2009b, Evans and Campbell 2002, Potter et al. 2007). The subfamily Rosoideae, which contains rose, raspberry, and strawberry, has $x=7$. The tribe Amygdaleae of subfamily Amygdaloideae, known for almond, apricot, cherry, peach, and plum, has $x=8$. The former subfamily Spiraeoideae (tribe Spiraeeae of subfamily Amygdaloideae,) has $x=9$. Basic chromosome number $x=17$ is observed for the tribe Pyreae of subfamily Amygdaloideae, which contains apple, loquat, pear, and quince. Challice $(1974,1981)$ suggested that the Pyreae was generated by an allopolyploidization event between "Amygdaleae" $(x=8)$ and "Spiraeeae" $(x=9)$. Recent molecular genetic studies contradicted the allopolyploidization and supported the autopolyploid origin of hybridization between closely related members of Spiraeeae (Evans and Campbell 2002). Velasco et al. (2010) 
showed that a relatively recent (ca. 50 million years ago) genome-wide duplication resulted in the transition from nine ancestral chromosomes to 17 chromosomes in apple, based on whole-genome sequencing analysis.

In recent years, international collaborative studies by the Rosaceae research community have hastened progress in developing genetic and genomic resources for representative crops such as apple $(M . \times$ domestica $)$, peach $($. persica $)$, and strawberry (Fragaria spp.) (Shulaev et al. 2008); this strategy was based on a consensus that there are multiple Rosaceae model species (Dirlewanger et al. 2009b). These resources, including expressed sequence tags (ESTs), bacterial artificial chromosome (BAC) libraries, physical and genetic maps, and molecular markers and bioinformatics tools, are available through the Genome Database for the Rosaceae (GDR; http://www.rosaceae.org). The availability of this database has rendered various rosaceous crops highly amenable to functional and comparative genomics studies. Here we review recent progress in genomics studies on Rosaceae fruit trees such as apple, pear, peach, and cherry, and we discuss the newly accumulated knowledge and resources for comparative genomics studies on this family.

\section{Genome sequences of Rosaceae fruit crops}

Whole-genome sequences have been reported for Chinese pear (Wu et al. 2013), European pear (Chagné et al. 2014), apple (Velasco et al. 2010), peach (Verde et al. 2013), Japanese apricot (Zhang et al. 2012), wild strawberry (Shulaev et al. 2011) and cultivated strawberry (Hirakawa et al. 2014) (Table 1). The draft genome of the Chinese pear 'Dangshansuli' (P. bretschneideri) is now available (Wu et al. 2013). A total of 2103 scaffolds span $512.0 \mathrm{Mb}(97.1 \%$ of the estimated genome size, $527 \mathrm{Mb}$ ) and are not anchored to the 17 chromosomes. The Chinese pear genome assembly contains 42,812 protein-coding genes, and about $28.5 \%$ of them encode multiple isoforms. The identified repetitive sequences $(271.9 \mathrm{Mb}$ in total) account for $53.1 \%$ of the genome. The difference in size between the pear and apple genomes is mainly due to the presence of repetitive sequences (predominantly transposable elements), whereas genic regions and protein-coding genes are similar in both species. A draft genome assembly of European pear 'Bartlett' (Chagné et al. 2014) contains 142,083 scaffolds and covers a total of $577.3 \mathrm{Mb}(96.2 \%$ of the estimated genome size, $600 \mathrm{Mb}$ ). A total of 43,419 putative genes were predicted, of which 1219 are unique to European pear and are not found in other dicots plant genomes sequenced. Analysis of the expansin gene family and other cell wallrelated genes showed their involvement in fruit softening in both European pear and apple. It is expected that pear genome sequences of Chinese and European pears will be assigned to 17 pseudo-chromosomes, which will greatly help us to conduct genetics and genomics studies in pears.

An international consortium has published a draft genome sequence of the domesticated apple 'Golden Delicious', a common founder cultivar in many breeding programs (Velasco et al. 2010). The genome assembly of 'Golden Delicious' consists of 122,146 contigs spanning a total of $603.9 \mathrm{Mb}(81.3 \%$ of the estimated genome, $742.3 \mathrm{Mb}$ ). Seventeen pseudo-chromosomes (GDR, Malus $\times$ domestica Genome v1.0p) were obtained from these contigs. A total of 57,386 putative protein-coding genes were predicted. The MADS-box gene family involved in flower and fruit development is expanded in apple to 15 members. The other gene families related with transport and assimilation of sorbitol are also expanded, and are involved in Rosaceae-specific metabolism.

A high-quality draft reference genome sequence, Peach v1.0, of the doubled haploid genotype of the peach cultivar 'Lovell' has been reported (Verde et al. 2013). Since 'Lovell' is completely homozygous, its genome assembly has facilitated obtaining a reliable and unbiased reference genome. Using 827 markers from an updated Prunus reference map (Howad et al. 2005), Verde et al. (2013) organized $215.9 \mathrm{Mb}$ of the Peach v1.0 genome into eight pseudomolecules covering $81.5 \%$ of the estimated genome $(265 \mathrm{Mb})$. A total of 27,852 protein-coding genes were predicted. Furthermore, comparative analyses showed that the ancestral triplicated blocks in peach are detected, and that putative paleoancestor regions are detectable.

The genome of Japanese apricot or mei (P. mume) was one of the first genomes to be sequenced in the subgenus Prunus of the genus Prunus (Zhang et al. 2012). Japanese apricot was domesticated in China more than 3000 years ago as an ornamental plant and fruit tree. A $237-\mathrm{Mb}$ genome assembly was generated from 29,989 scaffolds, $84.6 \%$ of which were further anchored to eight chromosomes in a

Table 1. Details of whole-genome sequencing in Rosaceae crops

\begin{tabular}{|c|c|c|c|c|c|c|}
\hline & Pyrus bretschneideri & Pyrus communis & Malus $\times$ domestica & Prunus persica & Prunus mume & Fragaria vesca \\
\hline Common name & Chinese pear & European pear & apple & peach & Japanese apricot & woodland strawberry \\
\hline Cultivar name & Dangshansuli & Bartlett & Golden Delicious & Lovell & BJFU1210120008 & Hawaii 4 (PI551572) \\
\hline No. of contigs & 25,312 & 182,196 & 122,146 & - & 45,592 & - \\
\hline No. of scaffolds & 2103 & 142,083 & - & 391 & 29,989 & 3263 \\
\hline Genome assembly size (Mb) & 512.0 & 577.3 & 603.9 & 215.9 & 237 & 209.8 \\
\hline Coverage $(\%)$ & 97.1 & 96.2 & 81.3 & 81.5 & 84.6 & 95 \\
\hline Estimated genome size $(\mathrm{Mb})$ & 527 & 600 & 742.3 & 265 & 280 & 240 \\
\hline No. of putative genes & 42,812 & 43,419 & 57,386 & 27,852 & 31,390 & 34,809 \\
\hline No. of pseudo-chromosomes & - & - & 17 & 8 & 8 & 7 \\
\hline Reference & Wu et al. 2013 & Chagné et al. 2014 & Velasco et al. 2010 & Verde et al. 2013 & Zhang et al. 2012 & Shulaev et al. 2011 \\
\hline
\end{tabular}


genetic map constructed by restriction-site-associated DNA sequencing (RADseq); 31,390 protein-coding genes were annotated and integrated using $a b$ initio gene prediction methods. By comparison of the P. mume genome with the available data, nine ancestral chromosomes of the Rosaceae family were reconstructed (Zhang et al. 2012).

Strawberry is one of the most important Rosaceae crops, and genomes were sequenced for wild woodland strawberry (Shulaev et al. 2011) and cultivated octoploid strawberry (Hirakawa et al. 2014). The woodland strawberry F. vesca $(2 n=2 x=14)$, a diminutive herbaceous perennial, has a small genome $(240 \mathrm{Mb})$ that shares substantial sequence identity with the genomes of the cultivated strawberry $(F . \times$ ananassa $)$ and other economically important rosaceous plants. A total of $209.8 \mathrm{Mb}(>95 \%)$ of the genome sequence were included in 272 representative scaffolds out of 3262 scaffolds, which were anchored to seven pseudochromosomes in the genetic linkage map. Gene prediction modeling identified 34,809 putative protein-coding genes. Macrosyntenic relationships between Fragaria $(x=7)$ and Prunus $(x=8)$ predict a hypothetical ancestral Rosaceae genome that had nine chromosomes. Furthermore, the whole genome sequences of peach, apple and strawberry were analyzed and compared by using 1399 orthologous regions between the three genomes, suggesting the ancestral genome $(x=9)$ to the extant Fragaria, Prunus and Malus genomes (Illa et al. 2011, Jung et al. 2012).

\section{Genome-wide molecular markers}

\section{SSR markers}

Simple sequence repeat (SSR) markers, or microsatellites, provide a reliable method for evaluation of genetic diversity and construction of genetic maps because of their co-dominant inheritance and the allelic abundance (Weber and May 1989). More than 1000 SSR markers have been developed in Japanese and European pears from genome sequences (Fernández-Fernández et al. 2006, Inoue et al. 2007, Sawamura et al. 2004, Yamamoto et al. 2002a, 2002b, 2002c ), ESTs (Nishitani et al. 2009, Zhang et al. 2014), and next-generation sequencing (NGS) data (Yamamoto et al. 2013). Recently, a large number of SSR markers have been developed from the whole-genome sequence of Chinese pear 'Dangshansuli' (Chen et al. 2015). SSR markers developed in pear have been often used as anchor loci for reference genetic linkage maps of pear (Chen et al. 2015, Yamamoto et al. 2007).

In apple, hundreds of SSR markers have been developed (Celton et al. 2009, Gianfranceschi et al. 1998, Guilford et al. 1997, Liebhard et al. 2002, 2003, Moriya et al. 2012, Silfverberg-Dilworth et al. 2006, van Dyk et al. 2010) and used to construct high-quality genetic linkage maps with high marker density. Among Prunus spp., a large number of SSR markers have been developed for peach and almond (Aranzana et al. 2002, 2003, Cipriani et al. 1999, Dirlewanger et al. 2002, Howad et al. 2005, Nishitani et al.
2007, Sosinski et al. 2000, Testolin et al. 2000, Yamamoto et al. 2002d, 2003, 2005), cherries (Cantini et al. 2001, Downey and Iezzoni 2000, Joobeur et al. 2000, Struss et al. 2002), and apricot (Lopes et al. 2002).

\section{SNP markers}

Although at present SSR markers seem to be the best choice for genetics and genomics studies, marker systems with even higher throughput, such as single-nucleotide polymorphisms (SNPs), have been developed based on whole-genome sequencing data. Using NGS technology, Montanari et al. (2013) have developed 1096 SNPs from three European pear cultivars. A total of 857 polymorphic SNP markers were validated and mapped using a segregating population of European pear 'Old Home' $\times$ 'Louise Bon Jersey' and interspecific breeding families derived from Asian (P. pyrifolia and P. bretschneideri) and European pear pedigrees. Japanese pear 'Housui' (syn. 'Hosui') has also been used for EST sequencing of $185 \mathrm{Mb}$ and genome sequencing of $529 \mathrm{Mb}$ (Terakami et al. 2014). Using the GoldenGate assay, Terakami et al. (2014) evaluated 1536 SNPs detected in EST and genome sequences of 'Housui', and mapped 609 SNPs on its linkage map. Using RADseq, Wu et al. (2014) have genotyped Chinese pear SNPs by NGS and mapped 3143 SNPs on a linkage map.

The 8K apple Infinium SNP chip has been developed by the USA-based international research program RosBREED (Chagné et al. 2012). To discover genome-wide SNPs, 27 apple cultivars were chosen to represent worldwide breeding germplasms and were re-sequenced at low coverage by NGS technology. Of 2,113,120 SNPs detected, 7867 were selected for the apple 8K SNP array; after evaluation in segregating families and a germplasm collection, 5554 were found to be polymorphic (Chagné et al. 2012). Despite this progress, the number of robust and evenly distributed SNP markers in the $8 \mathrm{~K}$ array was not sufficient. Recently, a $20 \mathrm{~K}$ SNP array has been developed by the European research program FruitBreedomics, which focuses on bridging the gap between breeding and genomics (Bianco et al. 2014). This SNP array has been developed to enable high-precision genomewide association analyses and pedigree-based analysis because of rapid decay of linkage disequilibrium. The SNPs included in this array were predicted from re-sequencing data derived from the genome sequences of 13 apple cultivars and one accession of crab apple (M. micromalus).

Using NGS technology, the International Peach SNP Consortium has re-sequenced the whole genomes of 56 peach breeding accessions (Verde et al. 2012, 2013) and developed a 9K SNP array (Verde et al. 2012). Using the GoldenGate assay, Martínez-García et al. (2013) have evaluated a set of 1536 SNPs of peach (P. persica) developed from the whole-genome sequences of three cultivars. The RosBREED Consortium has also developed a 6K SNP array for diploid sweet cherry (P. avium) and allotetraploid sour cherry (P. cerasus) (Peace et al. 2012). 


\section{Reference genetic linkage maps}

High-density reference genetic linkage maps constructed with genome-wide molecular markers are important for many genetic and breeding applications in Rosaceae fruit trees including marker-assisted selection (MAS), mapping of quantitative trait loci (QTLs), identifying DNA markers for fingerprinting, and map-based gene cloning. Because good, comprehensive books and reviews have been produced that describes mendelian traits and QTLs in Rosaceae fruit trees (Dirlewanger et al. 2009a, Korban and Tartarini 2009, Salazar et al. 2014), it would be impractical to repeat that information. Instead we describe high-density reference genetic linkage maps in pear, apple and Prunus.

\section{Pear reference maps}

Among Pyrus spp., integrated high-density genetic linkage maps are available for the European pear cultivars 'Bartlett' and 'La France' and the Japanese pear cultivar 'Housui'; these maps are based on SSRs from pear, apple, and Prunus, amplified fragment length polymorphisms (AFLPs), isozymes, and phenotypic traits (Terakami et al. 2009, Yamamoto et al. 2002c, 2004a, 2007). The linkage maps of 'Bartlett', 'La France', and 'Housui' consisted of 447, 414, and 335 marker loci, respectively, and covered 17 linkage groups (LGs), which matched the basic chromosome number of pear $(x=17)$. Recently, Terakami et al. (2014) established a SNP assay to evaluate 1536 SNPs detected in the EST and genome sequences of 'Housui', and mapped 609 SNPs on a linkage map of 'Housui'. After all available SNP and SSR markers were integrated, the latest version of updated reference genetic linkage map of 'Housui' was reconstructed (Fig. 1), which consists of 1033 loci, including 609 SNPs from transcriptome and genome analyses, 61 SNPs from potential intron polymorphism markers (Terakami et al. 2013), 202 pear SSRs, 141 apple SSRs, and 20 other markers. Montanari et al. (2013) evaluated a set of 1096 European pear SNPs and 7692 apple SNPs, and mapped 857 and 1031 SNPs, respectively, on pear genetic maps. On the basis of whole-genome sequencing of $P$. bretschneideri, Chen et al. (2015) constructed a consensus genetic map consisting of 734 SSR loci derived from 1341 newly designed SSRs. Using RADseq, Wu et al. (2014) mapped 3143 SNPs on linkage maps of Chinese pear.

\section{Apple reference maps}

Several apple reference genetic linkage maps have been published. The first RFLP-based reference maps for 'Prima' and 'Fiesta' were constructed using $152 \mathrm{~F}_{1}$ individuals and the two maps were aligned using 67 multi-allelic markers (Maliepaard et al. 1998). SSR-based integrated genetic linkage maps for 'Fiesta' and 'Discovery' were constructed using 840 molecular markers including 129 SSRs (Liebhard et al. 2002, 2003). A new set of 148 apple microsatellite markers has been developed and mapped on the reference linkage maps of 'Fiesta' and 'Discovery' (Silfverberg-
Dilworth et al. 2006). Recently, the 8K Infinium SNP chip described above was used to construct a high-density genetic linkage map in apple (Chagné et al. 2012). In the FruitBreedomics project, 21 full sib families were SNPgenotyped, resulting in the genetic mapping of approximately 15,800 SNP markers (Bianco et al. 2014).

\section{Prunus reference maps}

The framework Prunus mapping population for construction of the reference map was an $\mathrm{F}_{2}$ population (referred to as the $\mathrm{T} \times \mathrm{E}$ population) produced by crossing almond (Prunus dulcis) 'Texas' $\times$ peach $($ P. persica) 'Earlygold' and selfing a single $F_{1}$ plant (MB 1-73) (Joobeur et al. 1998). The $\mathrm{T} \times \mathrm{E}$ map contained 562 marker loci (Dirlewanger et al. 2004a). Howad et al. (2005) established a Prunus reference map using a set of six $\mathrm{F}_{2}$ plants, one $\mathrm{F}_{1}$ hybrid, and one parent of the $\mathrm{F}_{1}$ hybrid, which could jointly define 65 possible different genotypes by the markers mapped on the $\mathrm{T} \times \mathrm{E}$ map. Howad et al. (2005) identified and mapped 264 SSR markers from 401 different SSR primer pairs. Recently, Verde et al. (2013) have aligned the eight main scaffolds (pseudo-chromosomes) against the updated version of the Prunus reference map constructed by Howad et al. (2005).

A consensus cherry genetic linkage map has been developed using 94 individuals from an interspecific cross, 'Napoleon' $(P$. avium $) \times P$. nipponica accession F1292; this map consisted of 174 loci, including 160 SSR loci and 6 gene-specific markers, and covered $680 \mathrm{cM}$ (Clarke et al. 2009). Cabrera et al. (2012) developed a sweet cherry (P. avium) reference linkage map using Rosaceae Conserved Orthologous Set (RosCOS) markers and SSR markers. RosCOS markers were identified from 3818 rosaceous unigenes comprised of two or more ESTs corresponding to single-copy genes in Arabidopsis (Cabrera et al. 2009, 2012). Of the 627 RosCOS markers, 81 SNPs representing 68 genome-wide RosCOS were mapped in four $\mathrm{F}_{1}$ populations and placed on the consensus sweet cherry linkage map that included previously reported SSRs, indel, and S-RNase markers and spanned $779.4 \mathrm{cM}$. Klagges et al. (2013) constructed SNP-based high-density genetic maps of sweet cherry using intraspecific progenies from crosses between parental lines 'Black Tartarian' $\times$ 'Kordia' $(\mathrm{BT} \times \mathrm{K})$ and 'Regina' $\times$ 'Lapins' $(\mathrm{R} \times \mathrm{L})$. Of 5696 SNP markers tested, 723 and 687 were mapped onto eight LGs in BT $\times \mathrm{K}$ and $\mathrm{R} \times \mathrm{L}$, respectively. The obtained maps spanned 752.9 and $639.9 \mathrm{cM}$, with an average distance between markers of 1.1 and $0.9 \mathrm{cM}$, respectively. Very recently, genotyping-bysequencing (GBS), a new methodology based on highthroughput sequencing, was applied for genome mapping in sweet cherry (Guajardo et al. 2015).

\section{Marker-assisted selection in Japanese pear}

MAS can accelerate selection and reduce the progeny size and the cost of raising individuals to maturity in the field, especially in fruit trees (Luby and Shaw 2001). In Japanese 

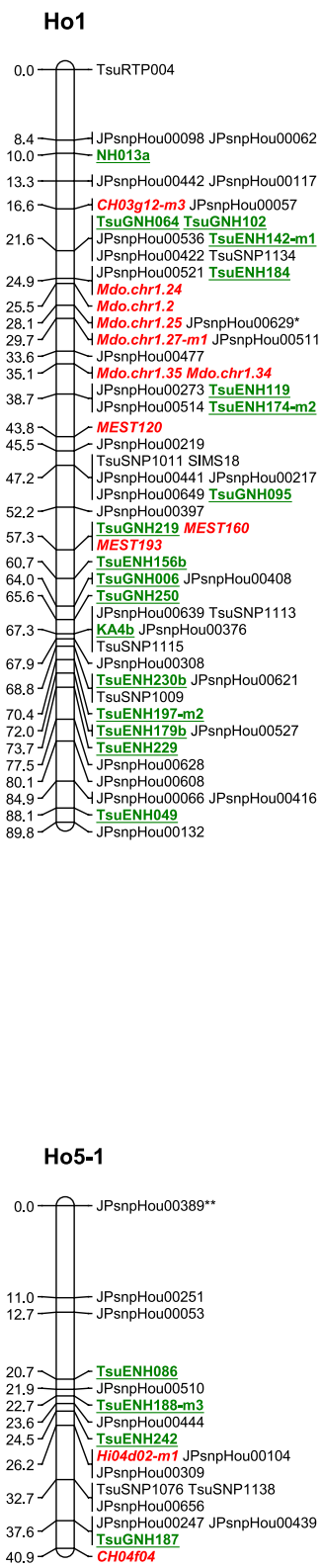

\section{Ho5-2}

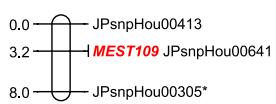

\section{Ho2-1}

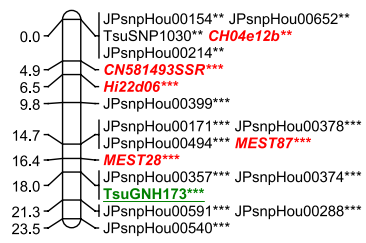

Ho2-2

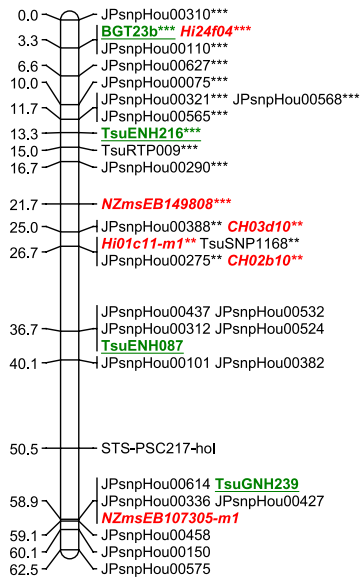

Ho3

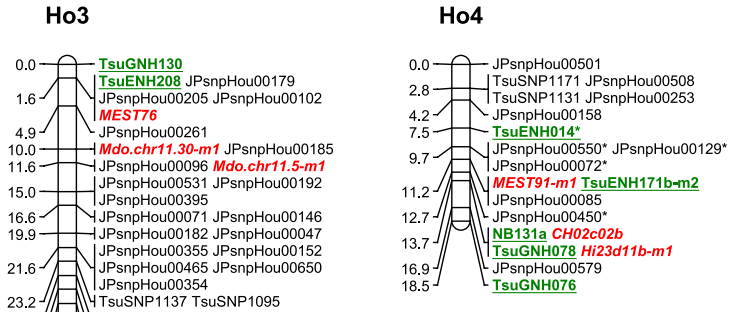

$24.9])$ [ [ - JPSnpHou00175

28.2 UTsuGNH186 JPsnpHou00095

9.8
JPsnpHou00092 JPsnpHou00272
JPsnpHou00469 JPsnpHou00556

6 I TSUENH186-m1 CHO2d08

38.3 4 NHO23a JPsnpHou00292

40.0 4JPsnpHou00645 TsuENH246

41.6 $\int$ TsuGNH153 JPsnpHou00142

45.0 .

48.3 $\begin{aligned} & \text { TsuENH111 } \\ & \text { TsuENHO74 TsuGNH220 }\end{aligned}$

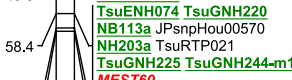

.1 MEST60

$\left.\begin{array}{l}60.1 \\ 60.5\end{array}\right]\left[\begin{array}{l}\text { Mdo.chr1.28 } \\ \text { JPsnpHou00215* } \\ \text { JPsnpHow0048 }\end{array}\right.$

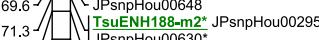

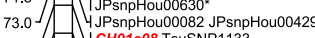

6.3 U JPsnpHou00188 JPsnpHou00351

79.6 作 UPsnpHou00544 NB109a

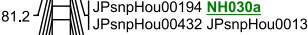

82.9 - JPsnpHouO0245

84.5 4 N NHO24b-m2 JPsnpHou00594

8.2. 8.8 JPSnpHouOO551

$\left.\begin{array}{l}87.8 \\ 91.1\end{array}\right]$ JMEST80 MS14h03

$92.8]-\left[\begin{array}{l}\text { M MEST80 MS14h03 } \\ \text { JPSnpHou00604 }\end{array}\right.$

95.9 1 - HGA8b 2000121 JPsnpHou00411

f JPSnPHou00174

102.8 $]$ [JPsnpHou0030

106.1
1.JPnpHou00356 JPsnpHou00301
CHO3g12-m4 JPsnpHou00387

Ho7

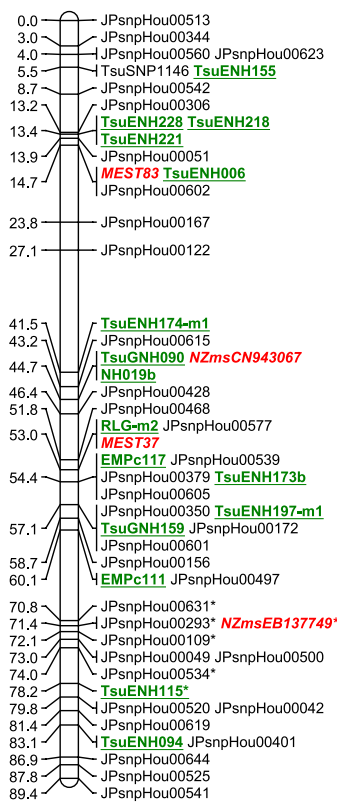

Ho8

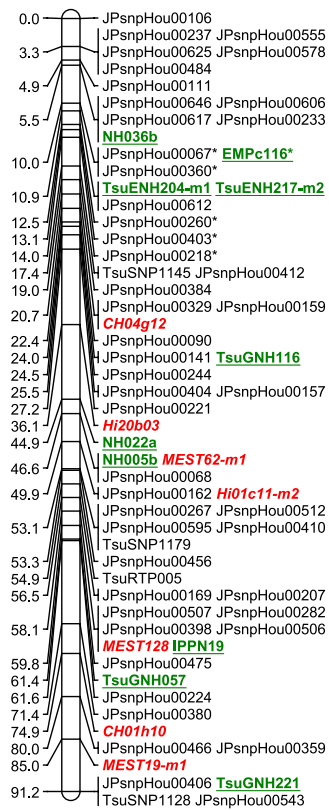

Fig. 1. The latest version of integrated reference genetic linkage map of Japanese pear 'Housui' based on SNP and SSR markers. A total of 81 SSR loci including 67 from pear ESTs or 454 genome sequencing analysis and 14 from apple, which were included in the 'Housui' map of Yamamoto et al. (2013), were added to the recently published SNP-based map (Terakami et al. 2014). Linkage groups are designated as Ho1 to Ho17, HoX1 and HoX2. The number to the left of each marker indicates genetic distance (cM). SSR markers (green, underlined) were developed from pear. SSR markers (red, italicized) were developed from apple. SNP markers developed by transcriptome analysis are denoted by JPsnpHou and SNP markers developed from potential intron polymorphism markers are denoted by TsuSNP. Distorted segregation is indicated by a significant $\mathrm{P}$ value of the $\chi^{2}$ test: $* \mathrm{P}=0.05, * * \mathrm{P}=0.01, * * * \mathrm{P}=0.005$. 


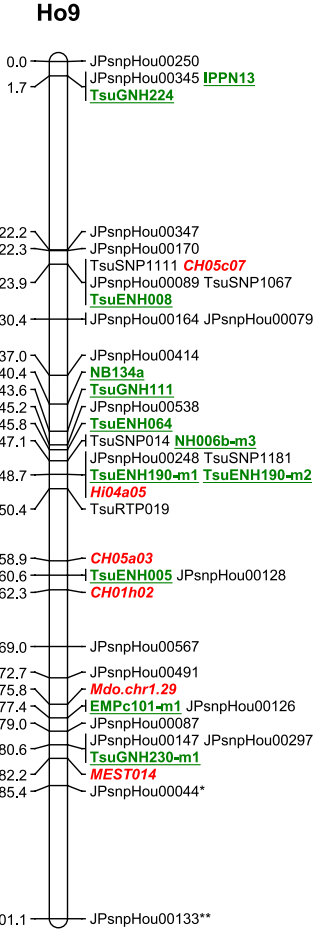

Ho13

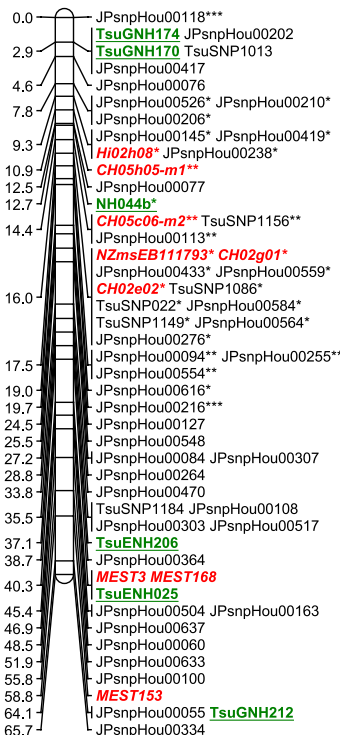

Ho10

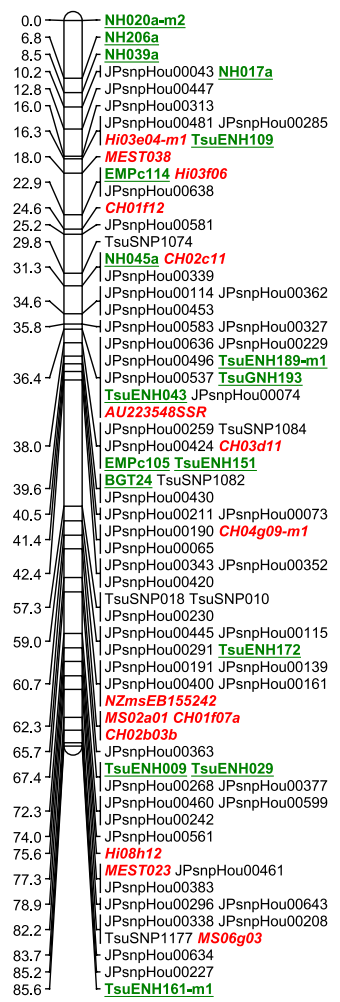

Ho14

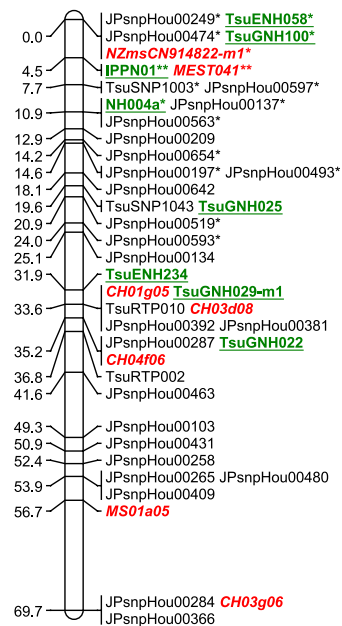

Ho11

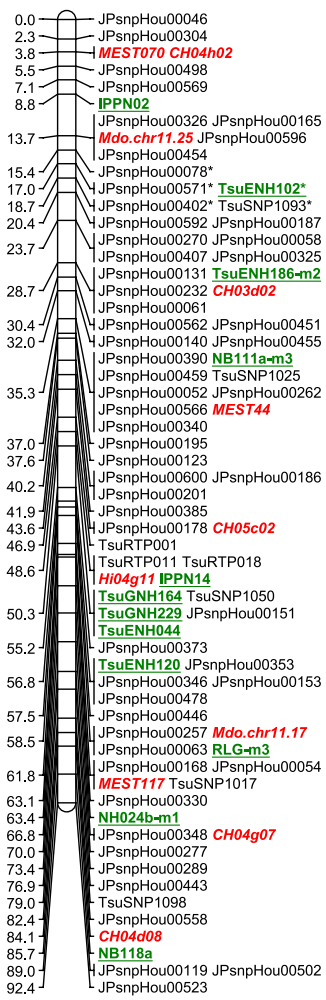

Ho15

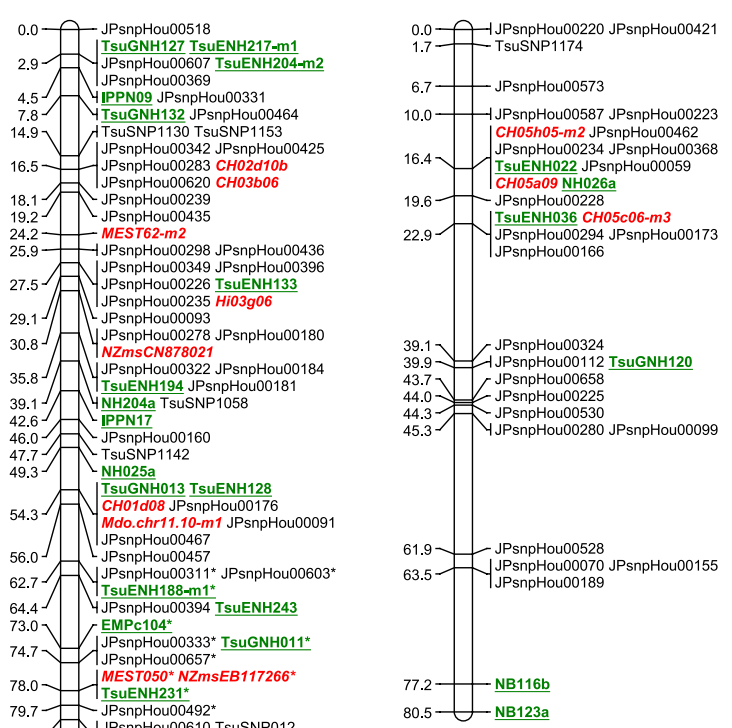

Ho12-1

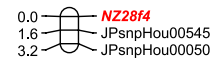

Ho12-2

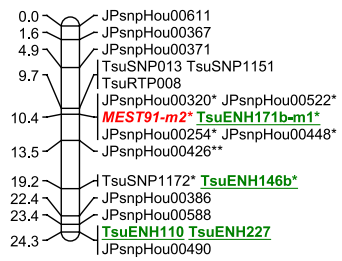

Ho16

Fig. 1. (continued) 

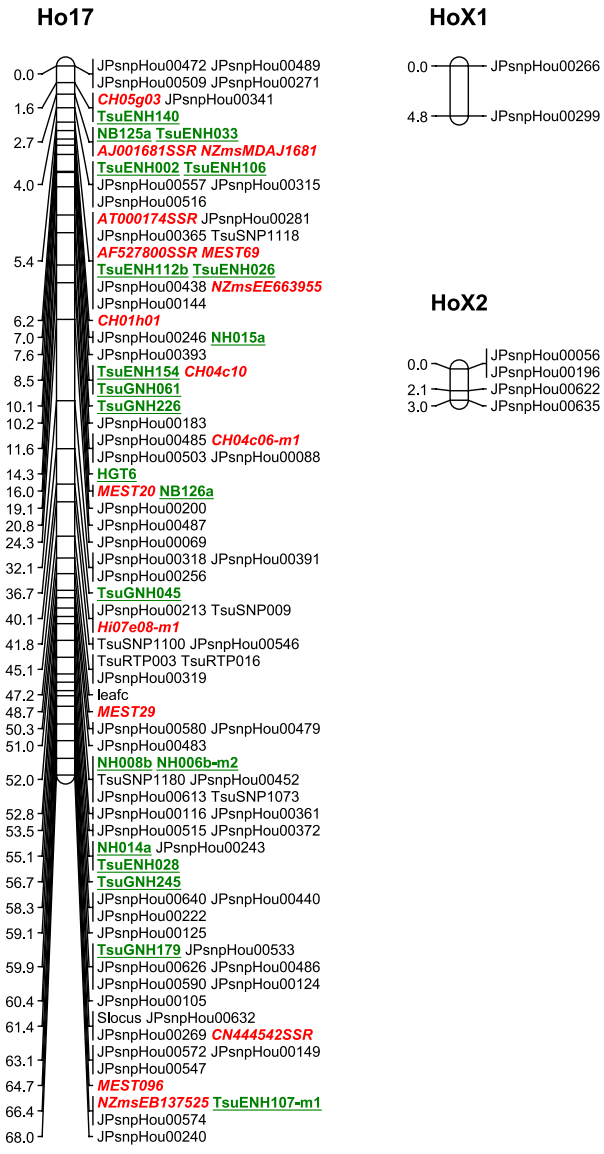

HoX2

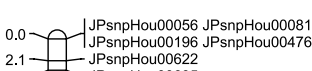
$2.1{ }_{3.0}{ }_{\text {JPsnpH HouO00622 }}$

Fig. 1. (continued)

pear, several molecular markers associated with genes of interest traits have been identified and used for MAS in practical breeding programs of the National Agriculture and Food Research Organization (NARO) Institute of Fruit Tree Science, Japan (Table 2). Since several characteristics were al- ready analyzed by genome mapping, QTL analysis, or both, the positions of responsible genes (loci) were identified in genetic linkage maps and tightly linked molecular markers were identified; these data are deposited in the public database of the Applied Crop Genomics Research Center (http:// www.naro.affrc.go.jp/genome/index.html). DNA markers have been identified that are associated with genes for resistance to scab disease caused by Venturia nashicola (Gonai et al. 2012, Iketani et al. 2001, Terakami et al. 2006) and for resistance (or susceptibility) to black spot disease caused by a Japanese pear pathotype of Alternaria alternata (Banno et al. 1999, Iketani et al. 2001, Terakami et al. 2007). Self-incompatibility in Japanese pear is controlled by a single multi-allelic $S$-locus, and $S$-genotype identification is important for breeding and selection of pollen donors for fruit production. Several molecular assays for rapid and reliable $S$-genotype determination have been established, such as polymerase chain reaction-restriction fragment length polymorphism (PCR-RFLP) analysis (Ishimizu et al. 1999) and allele-specific PCR amplification (Nashima et al. 2015). The $S_{4}{ }^{s m}$ allele of the self-compatible cultivar 'OsaNijisseiki' (a mutant of the self-incompatible cultivar 'Nijisseiki') has been identified and found to lack a 236-kbp genomic region that includes the $S_{4}-R N a s e$ coding region (Okada et al. 2008). Molecular markers associated with the following fruit-related traits were also revealed: fruit storage potential controlled by ethylene production (the 1aminocyclopropane-1-carboxylate [ACC] synthase gene; Itai et al. 2003), fruit skin color (Inoue et al. 2006, Yamamoto et al. 2014), and harvest time (Yamamoto et al. 2014). These markers can be used for MAS in Japanese pear breeding programs.

\section{Synteny in Rosaceae fruit trees}

It is expected that comparative genomics in Rosaceae fruit

Table 2. Molecular markers associated with genes of interest in Japanese pear and their positions in genetic linkage maps

\begin{tabular}{|c|c|c|c|c|c|c|c|}
\hline Characteristics & Gene symbol & Gene sources & $\begin{array}{l}\text { Linkage } \\
\text { group nos. }\end{array}$ & $\begin{array}{c}\text { Associsted molecular } \\
\text { markers (Accession nos.) }\end{array}$ & $\begin{array}{l}\text { F-primer sequences } \\
\qquad\left(5^{\prime}-3^{\prime}\right)\end{array}$ & $\begin{array}{l}\text { R-primer sequences } \\
\qquad\left(5^{\prime}-3^{\prime}\right)^{a}\end{array}$ & References \\
\hline \multirow[t]{3}{*}{$\begin{array}{l}\text { Scab resistance to } \\
\text { V. nashicola }\end{array}$} & \multirow[t]{3}{*}{$V n k$} & \multirow[t]{3}{*}{ Kinchaku } & \multirow[t]{3}{*}{1} & TsuENH184 (AB621908) & cctccctcagtacccatcaa & GTTTCTTtgaactccttcactcaccttcc & \multirow[t]{3}{*}{$\begin{array}{l}\text { Gonai et al. } 2012 \text {, } \\
\text { Terakami et al. } 2006\end{array}$} \\
\hline & & & & TsuENH101 (AB621905) & tgcctaatggaagggtccta & GTTTCTTcaaggaagagaagaccgacg & \\
\hline & & & & TsuENH157 (AB621907) & tagcagcagctctcctccac & GTTTCTTgtcagcacccctctgatgtt & \\
\hline \multirow{5}{*}{$\begin{array}{l}\text { Black spot } \\
\text { susceptibility }\end{array}$} & $A$ & Osa Nijisseiki & 11 & CMNB41/2350 & gacagcgtccta & \multirow{5}{*}{$\begin{array}{l}\text { ctcaaggatttcatgcccac } \\
\text { GTTTCTTactacatttttagatttgtgcgtc } \\
\text { ctcaaggatttcatgcccac } \\
\text { GTTTCTTactacatttttagatttgtgcgtc }\end{array}$} & Banno et al. 1999 \\
\hline & Ani & Osa Nijisseiki & 11 & $\mathrm{CH} 04 \mathrm{~h} 02$ & ggaagctgcatgatgagacc & & Terakami et al. 2007 \\
\hline & & & & $\mathrm{CH} 03 \mathrm{~d} 02$ & aaactttcactttcacccacg & & \\
\hline & Ana & Nansui & 11 & $\mathrm{CH} 04 \mathrm{~h} 02$ & ggaagctgcatgatgagacc & & Terakami et al. 2007 \\
\hline & & & & $\mathrm{CH} 03 \mathrm{~d} 02$ & aaactttcactttcacccacg & & \\
\hline Self-incompatibility & $S$ & Japanese pear & 17 & S-RNase & tttacgcagcaatatcag & acrttcggccaaataatt & $\begin{array}{l}\text { Ishimizu et al. } 1999 \text {, } \\
\text { Nashima et al. } 2015\end{array}$ \\
\hline Self-compatibility & $S_{4}{ }^{s m}$ & Osa Nijisseiki & 17 & SM & tcgtcttagggatttccaatgc & gccttaagggttcattgggc & Okada et al. 2008 \\
\hline \multirow[t]{2}{*}{ Fruit skin color } & & Niitaka & 8 & OPH-19-425 & ctgaccagcc & \multirow[b]{2}{*}{$\begin{array}{l}\text { caacccaactccagcaattt } \\
\text { caacaaaatgtgatcgccac }\end{array}$} & Inoue et al. 2006 \\
\hline & FruC & Akiakari & 8 & $\begin{array}{l}\text { Mdo.chr8.10 } \\
\text { CH04g12 }\end{array}$ & $\begin{array}{l}\text { tgcagccctcaaacttttct } \\
\text { caccgatggtgtcaacttgt }\end{array}$ & & Yamamoto et al. 2014 \\
\hline Fruit storage & PpACS2 & Japanese pear & 15 & ACC synthase & gtcacagaatcaacgattga & agtagaacgcgaaaacaaat & Itai et al. 2003 \\
\hline \multirow[t]{2}{*}{ Harvest time } & HarT-1 (QTL) & Taihaku & 3 & BGA35 (AB219799) & agagggagaaaggcgatt & \multirow{2}{*}{$\begin{array}{l}\text { GTTTCTTgettcatcaccgtctget } \\
\text { gctctcaaggetttcttctctc }\end{array}$} & Yamamoto et al. 2014 \\
\hline & HarT-2 (QTL) & Taihaku & 15 & PPACS2 & ggtatctttgtccggcaatc & & Yamamoto et al. 2014 \\
\hline
\end{tabular}

${ }^{a}$ GTTTCTT: pig tail sequence for DNA sequencer analysis. 
trees will be able to integrate conserved candidate genes, molecular markers associated with interest traits, and QTLs, in order to verify how the genetic and molecular factors control traits like fruit quality and texture across species and genera. Therefore, synteny or comparative genome mapping is an important approach, which determines the homologous genes of related species, as well as the co-linearity (conservation of the gene order) among conserved genomic regions.

\section{Co-linearity between Pyrus and Malus}

Yamamoto et al. (2001) applied apple SSR markers intergenerically for the characterization of several pear species (P. pyrifolia, P. bretschneideri, P. ussuriensis, P. communis, and $P$. calleryana). Nucleotide repeats were detected in the amplified fragments of pear and apple by both sequencing and Southern blot analyses, and the differences in fragment sizes between pear and apple were due mainly to the differences in the number of such repeats. The SSR markers are applicable across genera in the tribe Pyreae, subtribe Pyrinae, which includes apple, pear, quince (Cydonia oblonga Mill.), and loquat (Liebhard et al. 2002, Soriano et al. 2005, Yamamoto et al. 2001, 2004a, 2004b). When pear genetic linkage maps ('Bartlett' and 'La France') were compared with the apple reference maps ('Discovery' and 'Fiesta'), 66 apple SSR loci could be positioned onto the homologous LGs of pear (Yamamoto et al. 2007). Furthermore, SSR locus positions within LGs were almost identical in pear and apple, indicating good co-linearity in all 17 LGs. Gisbert et al. (2009) used SSR markers from apple and pear to construct genetic linkage maps of loquat cultivars 'Algerie' and 'Zaozhong-6'; the loquat maps showed a high synteny with apple maps when anchored SSR markers were used. Fukuda et al. (2014) identified almost perfect co-linearity of LG10 among loquat, pear, and apple. These findings suggest that all chromosomes of the genera in the tribe Pyreae show co-linearity despite considerable differences in the genome sizes, which range from $1.11 \mathrm{pg} / 2 \mathrm{C}$ to $1.57 \mathrm{pg} / 2 \mathrm{C}$ (Dickson et al. 1992, Dirlewanger et al. 2009b).

\section{Co-linearity within Prunus}

The marker transferability is extremely high within Prunus. For example, among 277 Prunus SSRs, including 141 from peach ( $P$. persica), 58 from apricot ( $P$. armeniaca), 31 from almond ( $P$. dulcis), 9 from sweet cherry ( $P$. avium), 4 from sour cherry ( $P$. cerasus), and 6 from Myrobalan plum (Prunus cerasifera Ehrh.), 95.3\% showed PCR amplification in Myrobalan plum (Dirlewanger et al. 2004a). Furthermore, Mnejja et al. (2010) examined Prunus SSR markers for transferability across rosaceous crops using nine species, almond $(P$. dulcis), peach $(P$. persica), apricot (P. armeniaca), Japanese plum (Prunus salicina Lindl.), European plum (Prunus domestica L.), sweet cherry (P. avium), apple $(M . \times$ domestica $)$, pear $(P$. communis $)$, and strawberry $(F \times$ ananassa $)$. Of the 145 SSRs derived from Prunus species, $83.6 \%$ of amplified bands of the expected size range were identified in other Prunus species, and the proportion of SSRs showing polymorphism was also high (63.9\%) (Mnejja et al. 2010). In contrast, only $16.3 \%$ of the Prunus SSRs were transferable across species of other Rosaceae genera such as apple, pear, and strawberry (Mnejja et al. 2010).

SSR markers developed for various Prunus species have been intensively used to compare Prunus linkage maps (Dirlewanger et al. 2004b). Detailed map comparisons were performed using common SSR markers between the reference genetic linkage map $\mathrm{T} \times \mathrm{E}$ (Joobeur et al. 2000) and the maps of $P$. armeniaca (Lambert et al. 2004), P. davidiana (Foulongne et al. 2003), and P. cerasifera (Dirlewanger et al. 2004a). The distribution and order of SSR markers in all Prunus species show complete synteny except for a reciprocal translocation between LGs 6 and 8 detected in peach and almond (Dirlewanger et al. 2004b, Jáuregui et al. 2001). The SNP-based sweet cherry maps displayed high synteny and co-linearity of all eight LGs with the Prunus reference map and with the peach genome v1.0 (Klagges et al. 2013).

\section{Synteny between Pyrus (Malus) and Prunus}

Transferability of SSR markers is very low between tribes, as shown by comparing Prunus and Pyrus (Malus). Cipriani et al. (1999) found that only $18 \%$ of peach SSRs showed amplified bands in apple. Similarly, Yamamoto et al. (2004a) observed that only $10 \%$ of the Prunus SSRs could be transferred to the genetic linkage maps of Pyrus ('Bartlett' and 'Housui'). Only one out of 15 apple SSR markers was transferable to Prunus (Liebhard et al. 2002). A total of 613 RosCOS markers were successfully amplified and mapped on the Prunus $\mathrm{T} \times \mathrm{E}$ reference map. These RosCOS markers will be useful for further investigations of syntenic relationships between Pyrus (Malus) and Prunus. Furthermore, several other reports have showed synteny within Rosaceae plants (Sargent et al. 2009, Vilanova et al. 2008) and Rosaceae vs. other family (Staton et al. 2015).

\section{Conclusion and perspectives}

In this manuscript, we describe to focus recent progress on whole-genome sequences, genome-wide SNP and SSR markers, construction of reference genetic linkage maps, and synteny studies in Rosaceae fruit trees, which will help us to develop new cultivars with desirable traits by MAS and new genomic-based strategies in breeding programs.

Genetic improvement of Rosaceae fruit trees is strongly hampered by their large tree size, long generation, an extended juvenile phase for seedling (Luby and Shaw 2001, Rikkerink et al. 2007). Therefore, it is considered that MAS and marker-assisted breeding can accelerate selection and reduce the progeny size and the cost of raising individuals to maturity in the field (Luby and Shaw 2001, Rikkerink et al. 2007). However, attempts to MAS in fruit tree breeding programs remain limited for a few simply inherited traits, because marker development for MAS via bi-parental QTL mapping is also hindered by the same complications. Newly 
developed high-throughput genotyping technologies such as SNP chips and genotyping using NGS have enabled new genomic-based strategies such as genome-wide association studies (GWAS), which are an alternative to bi-parental QTL mapping in long-lived perennials. Selection based on genomic predictions of breeding values, i.e., genomic selection (GS, Meuwissen et al. 2001) is another alternative for MAS. The robust and evenly distributed genome-wide SNP markers combined with reference genetic linkage maps, help us to use new genomic-based strategies such as GWAS and GS, which are now emerging as powerful tools in pear, apple, and forest tree breeding programs (Grattapaglia and Resende 2011, Iwata et al. 2013a, 2013b, Kumar et al. 2012, 2013).

\section{Literature Cited}

Aranzana, M.J., J. Garcia-Mas, J.Carbo and P.Arús (2002) Development and variability analysis of microsatellite markers in peach. Plant Breed. 121: 87-92.

Aranzana,M.J., A.Pineda, P.Cosson, E.Dirlewanger, J.Ascasibar, G.Cipriani, C.D. Ryder, R.Testolin, A.Abbott, G.J.King et al. (2003) A set of simple-sequence repeat (SSR) markers covering the Prunus genome. Theor. Appl. Genet. 106: 819-825.

Banno, K., H. Ishikawa, Y. Hamauzu and H. Tabira (1999) Identification of a RAPD marker linked to the susceptible gene of black spot disease in Japanese pear. J. Japan. Soc. Hort. Sci. 68: 476-481.

Bell, R.L., H.A. Quamme, R.E.C.Layne and R.M.Skirvin (1996) Pears. In: Janick, J. and J.N. Moore (eds.) Fruit breeding, vol I: Tree and tropical fruits. John Wiley \& Sons, London, pp. 441-514.

Bianco, L., A. Cestaro, D.J. Sargent, E. Banchi, S. Derdak, M.D. Guardo, S. Salvi, J.Jansen, R. Viola, I. Gut et al. (2014) Development and validation of a $20 \mathrm{~K}$ single nucleotide polymorphism (SNP) whole genome genotyping array for apple (Malus $\times$ domestica Borkh.). PLoS ONE 9: e110377.

Cabrera,A., A.Kozik, W.Howad, P.Arús, A. Iezzoni and E.van der Knaap (2009) Development and bin mapping of a Rosaceae Conserved Ortholog Set (COS) of markers. BMC Genomics 10: 562.

Cabrera,A., U.R.Rosyara, P.De Franceschi, A.Sebolt, S.S. Sooriyapathirana, E. Dirlewanger, J.Quero-Garcia, M. Schuster, A.F. Iezzoni and E.van der Knaap (2012) Rosaceae conserved orthologous sequences marker polymorphism in sweet cherry germplasm and construction of a SNP-based map. Tree Genet. Genomes 8: 237-247.

Cantini,C., A.F. Iezzoni, W.F.Lamboy, M. Bortizki and D. Struss (2001) DNA fingerprinting of tetraploid cherry germplasm using simple sequence repeats. J. Amer. Soc. Hort. Sci. 126: 205-209.

Celton, J.M., D.S. Tustin, D. Chagné and S.E. Gardiner (2009) Construction of a dense genetic linkage map for apple rootstocks using SSRs developed from Malus ESTs and Pyrus genomic sequences. Tree Genet. Genomes 5: 93-107.

Chagné, D., R.N. Crowhurst, M. Troggio, M.W.Davey, B. Gilmore, C. Lawley, S. Vanderzande, R.P. Hellens, S. Kumar, A. Cestaro et al. (2012) Genome-wide SNP detection, validation, and development of an 8K SNP array for apple. PLoS ONE 7: e31745.

Chagné, D., R.N. Crowhurst, M.Pindo, A.Thrimawithana, C.Deng, H. Ireland, M. Fiers, H. Dzierzon, A. Cestaro, P. Fontana et al. (2014) The draft genome sequence of European pear (Pyrus communis L. 'Bartlett'). PLoS ONE 9: e 92644.
Challice, J.S. (1974) Rosaceae chemotaxonomy and the origins of the Pomoideae. Bot. J. Linn. Soc. 69: 239-259.

Challice, J.S. (1981) Chemotaxonomic studies in the Rosaceae and the evolutionary origins of the subfamily Maloideae. Preslia 53: 289304.

Chen, H., Y. Song, L.T. Li, M.A. Khan, X.G. Li, S.S. Korban, J. Wu and S.L.Zhang (2015) Construction of a high-density simple sequence repeat consensus genetic map for pear (Pyrus spp.). Plant. Mol. Biol. Rep. 33: 316-325.

Cipriani, G., G.Lot, W.G.Huang, M.T.Marrazzo, E.Peterlunger and R. Testolin (1999) AC/GT and AG/CT microsatellite repeats in peach [Prunus persica (L) Batsch]: isolation, characterisation and cross-species amplification in Prunus. Theor. Appl. Genet. 99: 6572.

Clarke, J.B., D.J.Sargent, R.I.Bošković, A. Belaj and K.R. Tobutt (2009) A cherry map from the inter-specific cross Prunus avium 'Napoleon' $\times$ P. nipponica based on microsatellite, gene-specific and isoenzyme markers. Tree Genet. Genomes 5: 41-51.

Dickson, E.E., K.Arumuganathan, S. Kresovich and J.J.Doyle (1992) Nuclear DNA content variation within the Rosaceae. Am. J. Bot. 79: 1081-1086.

Dirlewanger,E., P.Cosson, M. Tavaud, M.J.Aranzana, C.Poizat, A.Zanetto, P.Arús and F. Laigret (2002) Development of microsatellite markers in peach [Prunus persica (L.) Batsch] and their use in genetic diversity analysis in peach and sweet cherry (Prunus avium L.). Theor. Appl. Genet. 105: 127-138.

Dirlewanger,E., P.Cosson, W.Howad, G.Capdeville, N.Bosselut, M. Claverie, R. Voisin, C. Poizat, B. Lafargue, O.Baron et al. (2004a) Microsatellite genetic linkage maps of Myrobalan plum and an almond-peach hybrid-location of root-knot nematode resistance genes. Theor. Appl. Genet. 109: 827-838.

Dirlewanger, E., E. Graziano, T. Joobeur, F. Garriga-Calderé, P. Cosson, W. Howad and P.Arús (2004b) Comparative mapping and markerassisted selection in Rosaceae fruit crops. Proc. Natl. Acad. Sci. USA 101: 9891-9896.

Dirlewanger, E., J. Claverie, A.F. Iezzoni and A. Wunsch (2009a) Sweet and Sour Cherries: Linkage Maps, QTL Detection and Marker Assisted Selection. In: Gardiner, S.E. and K.M.Folta (eds.) Plant Genetics/Genomics vol. 6: Genetics and Genomics of Rosaceae. Springer, New York, pp. 291-313.

Dirlewanger,E., B. Denoyes-Rothan, T. Yamamoto and D. Chagné (2009b) Genomics Tools across Rosaceae Species. In: Gardiner, S.E. and K.M. Folta (eds.) Plant Genetics/ Genomics vol 6: Genetics and Genomics of Rosaceae. Springer, New York, pp. 539-561.

Downey, S.L. and A.F. Iezzoni (2000) Polymorphic DNA markers in black cherry (Prunus serotina) are identified using sequences from sweet cherry, peach, and sour cherry. J. Amer. Soc. Hort. Sci. 125: 76-80.

Evans, R.C. and C.S.Campbell (2002) The origin of the apple subfamily (Maloideae; Rosaceae) is clarified by DNA sequence data from duplicated GBSSI genes. Am. J. Bot. 89: 1478-1484.

FAOSTAT (2013) http: //faostat.fao.org/

Fernández-Fernández, F., N.G.Harvey and C.M.James (2006) Isolation and characterization of polymorphic microsatellite markers from European pear (Pyrus communis L.). Mol. Ecol. Notes 6: 1039-1041.

Foulongne, M., T.Pascal, F.Pfeiffer and J.Kervella (2003) QTLs for powdery mildew resistance in peach $\times$ Prunus davidiana crosses: consistency across generations and environments. Mol. Breed. 12: $33-50$.

Fukuda, S., K. Ishimoto, S. Sato, S. Terakami, T. Yamamoto and 
N. Hiehata (2014) Genetic mapping of the loquat canker resistance locus in bronze loquat (Eriobotrya deflexa). Tree Genet. Genomes 10: 875-883.

Gianfranceschi, L., N. Seglias, R. Tarchini, M. Komjanc and C. Gessler (1998) Simple sequence repeats for the genetic analysis of apple. Theor. Appl. Genet. 96: 1069-1076.

Gisbert,A.D., J.Martínez-Calvo, G.Llácer, M.L.Badenes and C. Romero (2009) Development of two loquat [Eriobotrya japonica (Thunb.) Lindl.] linkage maps based on AFLPs and SSR markers from different Rosaceae species. Mol. Breed. 23: 523-538.

Gonai,T., S.Terakami, C.Nishitani, T.Yamamoto and M.Kasumi (2012) Fine mapping of the scab resistance gene of Japanese pear 'Kinchaku' for efficient marker-assisted selection. Bull. Ibaraki Plant Biotech. Inst. 12: 27-33.

Grattapaglia, D. and M.D.V.Resende (2011) Genomic selection in forest tree breeding. Tree Genet. Genomes 7: 241-255.

Guajardo, V., S. Solís, B. Sagredo, F. Gainza, C.Muñoz, K. Gasic and P. Hinrichsen (2015) Construction of high density sweet cherry (Prunus avium L.) linkage maps using microsatellite markers and SNPs detected by genotyping-by-sequencing (GBS). PLoS ONE 10: $\mathrm{e} 0127750$.

Guilford, P., S. Prakash, J.M.Zhu, E. Rikkerink, S. Gardiner, H. Bassett and R. Forster (1997) Microsatellites in Malus $\times$ domestica (apple): abundance, polymorphism and cultivar identification. Theor. Appl. Genet. 94: 249-254.

Hirakawa,H., K. Shirasawa, S. Kosugi, K. Tashiro, S. Nakayama, M. Yamada, M. Kohara, A. Watanabe, Y. Kishida, T. Fujishiro et al. (2014) Dissection of the octoploid strawberry genome by deep sequencing of the genomes of Fragaria species. DNA Res. 21: 169181.

Howad, W., T. Yamamoto, E. Dirlewanger, R. Testolin, P.Cosson, G. Cipriani, A.J.Monforte, L. Georgi, A.G.Abbott and P.Arús (2005) Mapping with a few plants: using selective mapping for microsatellite saturation of the Prunus reference map. Genetics 171: $1305-1309$.

Hummer, K.E. and J.Janick (2009) Rosaceae: Taxonomy, Economic Importance, Genomics. In: Gardiner, S.E. and K.M. Folta (eds.) Plant Genetics/ Genomics vol. 6: Genetics and Genomics of Rosaceae. Springer, New York, pp. 1-17.

Iketani,H., K.Abe, T.Yamamoto, K. Kotobuki, Y.Sato, T.Saito, O. Terai, N.Matsuta and T.Hayashi (2001) Mapping of diseaserelated genes in Japanese pear using a molecular linkage map with RAPD markers. Breed. Sci. 51: 179-184.

Illa, E., D.J. Sargent, E.L. Girona, J. Bushakra, A. Cestaro, R. Crowhurst, M. Pindo, A. Cabrera, E.van der Knaap, A. Iezzoni et al. (2011) Comparative analysis of rosaceous genomes and the reconstruction of a putative ancestral genome for the family. BMC Evol. Biol. 11: 9.

Inoue, E., M.Kasumi, F. Sakuma, H.Anzai, K.Amano and H.Hara (2006) Identification of RAPD marker linked to fruit skin color in Japanese pear (Pyrus pyrifolia Nakai). Sci. Hortic. 107: 254-258.

Inoue, E., Y.Matsuki, H.Anzai and K.Evans (2007) Isolation and characterization of microsatellite markers in Japanese pear (Pyrus pyrifolia Nakai). Mol. Ecol. Notes 7: 445-447.

Ishimizu, T., K. Inoue, M. Shimonaka, T. Saito, O. Terai and S. Norioka (1999) PCR-based method for identifying the S-genotypes of Japanese pear cultivars. Theor. Appl. Genet. 98: 961-967.

Itai,A., T. Kotaki, K. Tanabe, F. Tamura, D. Kawaguchi and M. Fukuda (2003) Rapid identification of 1-aminocyclopropane-1-carboxylate (ACC) synthase genotypes in cultivars of Japanese pear (Pyrus pyrifolia Nakai) using CAPS markers. Theor. Appl. Genet. 106 1266-1272.
Iwata,H., T.Hayashi, S.Terakami, N.Takada, Y.Sawamura and T. Yamamoto (2013a) Potential assessment of genome-wide association study and genomic selection in Japanese pear Pyrus pyrifolia. Breed. Sci. 63: 125-140.

Iwata, H., T. Hayashi, S. Terakami, N. Takada, T. Saito and T. Yamamoto (2013b) Genomic prediction of trait segregation in a progeny population: a case study of Japanese pear (Pyrus pyrifolia). BMC Genet. 14: 81

Jáuregui, B., M.C.de Vicente, R. Messeguer, A.Felipe, A. Bonnet, G. Salesses and P.Arús (2001) A reciprocal translocation between 'Garfi' almond and 'Nemared' peach. Theor. Appl. Genet. 102: 1169-1176.

Joobeur,T., M.A.Viruel, M.C.de Vicente, B.Jáuregui, J. Ballester, M.T.Dettori, I.Verde, M.J.Truco, R. Messeguer, I.Batlle et al. (1998) Construction of a saturated linkage map for Prunus using an almond $\times$ peach $F_{2}$ progeny. Theor. Appl. Genet. 97: 1034-1041.

Joobeur,T., N.Periam, M.C. de Vicente, G.J.King and P.Arús (2000) Development of a second generation linkage map for almond using RAPD and SSR markers. Genome 43: 649-655.

Jung, S., A. Cestaro, M. Troggio, D. Main, P.Zheng, I. Cho, K.M. Folta, B. Sosinski, A.Abbott, J.M. Celton et al. (2012) Whole genome comparisons of Fragaria, Prunus and Malus reveal different modes of evolution between Rosaceous subfamilies. BMC Genomics 13: 129.

Klagges, C., J.A.Campoy, J.Quero-Garc1a, A.Guzman, L. Mansur, E. Gratacos, H. Silva, U.R. Rosyara, A. Iezzoni, L.A. Meisel et al. (2013) Construction and comparative analyses of highly dense linkage maps of two sweet cherry intra-specific progenies of commercial cultivars. PLoS ONE 8: e54743.

Korban, S.S. and S. Tartarini (2009) Apple Structural Genomics. In: Gardiner, S.E. and K.M.Folta (eds.) Plant Genetics/ Genomics vol. 6: Genetics and Genomics of Rosaceae. Springer, New York, pp. 85-119.

Kumar, S., D.Chagné, M.C.A.M.Bink, R.K.Volz, C. Whitworth and C. Carlisle (2012) Genomic selection for fruit quality traits in apple (Malus $\times$ domestica Borkh.). PLoS ONE 7: e36674.

Kumar, S., D.J. Garrick, M.C.A.M. Bink, C. Whitworth, D. Chagné and R.K. Volz (2013) Novel genomic approaches unravel genetic architecture of complex traits in apple. BMC Genomics 14: 393.

Lambert, P., L.S.Hagen, P.Arús and J.M.Audergon (2004) Genetic linkage maps of two apricot cultivars (Prunus armeniaca L.) compared with the almond 'Texas' $\times$ peach 'Earlygold' reference map for Prunus. Theor. Appl. Genet. 108: 1120-1130.

Liebhard, R., L. Gianfranceschi， B. Koller, C.D. Ryder, R. Tarchini, E. Van De Weg and C. Gessler (2002) Development and characterisation of 140 new microsatellites in apple (Malus $\times$ domestica Borkh.). Mol. Breed. 10: 217-241.

Liebhard, R., B. Koller, L. Gianfranceschi and C. Gessler (2003) Creating a saturated reference map for the apple (Malus $\times$ domestica Borkh.) genome. Theor. Appl. Genet. 106: 1497-1508.

Lopes, M.S., K.M. Sefc, M. Laimer and A. Da Camara Machado (2002) Identification of microsatellite loci in apricot. Mol. Ecol. Notes 2: 24-26.

Luby, J.J. and D.V. Shaw (2001) Does marker-assisted selection make dollars and sense in a fruit breeding program? HortScience 36: 872-879.

Maliepaard,C., F.H.Alston, G. van Arkel, L.M.Brown, E. Chevreau, F. Dunemann, K.M.Evans, S. Gardiner, P.Guilford, A.W.van Heusden et al. (1998) Aligning male and female linkage maps of apple (Malus pumila Mill.) using multi-allelic markers. Theor. Appl. Genet. 97: 60-73. 
Martínez-García, P.J., D.E. Parfitt, E.A. Ogundiwin, J. Fass, H.M. Chan, R.Ahmad, S.Lurie, A. Dandekar, T.M. Gradziel and C.H. Crisosto (2013) High density SNP mapping and QTL analysis for fruit quality characteristics in peach (Prunus persica L.). Tree Genet. Genomes 9: 19-36.

Meuwissen, T.H.E., B.J.Hayes and M.E. Goddard (2001) Prediction of total genetic value using genome-wide dense marker maps. Genetics 157: 1819-1829.

Mnejja,M., J.Garcia-Mas, J.M.Audergon and P.Arús (2010) Prunus microsatellite marker transferability across rosaceous crops. Tree Genet. Genomes 6: 689-700.

Montanari, S., M. Saeed, M. Knabel, Y.K. Kim, M. Troggio, M. Malnoy, R. Velasco, P. Fontana, K.H. Won, C.E. Durel et al. (2013) Identification of Pyrus single nucleotide polymorphisms (SNPs) and evaluation for genetic mapping in European pear and interspecific Pyrus hybrids. PLoS ONE 8: e77022.

Moriya, S., H. Iwanami， N.Kotoda, T.Haji，K.Okada，S.Terakami, N. Mimida, T. Yamamoto and K.Abe (2012) Aligned genetic linkage maps of apple rootstock cultivar 'JM7' and Malus sieboldi 'Sanashi 63' constructed with novel EST-SSRs. Tree Genet. Genomes 8: 709-723.

Nashima, K., S. Terakami, S. Nishio, M. Kunihisa, C. Nishitani, T. Saito and T. Yamamoto (2015) $S$-genotype identification based on allelespecific PCR in Japanese pear. Breed. Sci. 65: 208-215.

Nishitani, C., T. Kimura, E. Ueda, W.Howad, P.Arús and T. Yamamoto (2007) Tri-/hexanucleotide microsatellite markers in peach derived from enriched genomic libraries and their application in Rosaceae. Breed. Sci. 57: 289-296.

Nishitani, C., S.Terakami, Y.Sawamura, N.Takada and T.Yamamoto (2009) Development of novel EST-SSR markers derived from Japanese pear (Pyrus pyrifolia). Breed. Sci. 59: 391-400.

Okada,K., N.Tonaka, Y.Moriya, N.Norioka, Y. Sawamura, T. Matsumoto, T.Nakanishi and T. Takasaki-Yasuda (2008) Deletion of a $236 \mathrm{~kb}$ region around $S_{4}$-RNase in a stylar-part mutant $S_{4}{ }^{s m}$ haplotype of Japanese pear. Plant Mol. Biol. 66: 389-400.

Peace,C., N. Bassil, D. Main, S. Ficklin, U.R.Rosyara, T. Stegmeir A. Sebolt, B. Gilmore, C. Lawley, T.C. Mockler et al. (2012) Development and evaluation of a genome-wide 6K SNP array for diploid sweet cherry and tetraploid sour cherry. PLoS ONE 7: e48305.

Potter,D., T.Eriksson, R.C.Evans, S.Oh， J.E.E.Smedmark，D.R Morgan, M.Kerr, K.R.Robertson, M.Arsenault, T.A. Dickinson et al. (2007) Phylogeny and classification of Rosaceae. Pl. Syst. Evol. 266: 5-43.

Rikkerink,E.H.A., N.C. Oraguzie and S.E. Gardiner (2007) Prospects of association mapping in perennial horticultural crops. In Oraguzie, N.C., E.H.A. Rikkerink, S.E. Gardiner and H.N. De Silva (eds.) Association Mapping in Plants. Springer, New York, pp. 249-269.

Salazar, J.A., D. Ruiz, J.A. Campoy, R. Sánchez-Pérez, C.H.Crisosto, P.J. Martínez-García， A. Blenda， S. Jung， D. Main, P. MartínezGómez et al. (2014) Quantitative trait loci (QTL) and mendelian trait loci (MTL) analysis in Prunus: a breeding perspective and beyond. Plant Mol. Biol. Rep. 32: 1-18.

Sargent, D.J., A. Marchese, D.W.Simpson, W. Howad, F. FernándezFernández, A. Monfort, P.Arús, K.M. Evans and K.R. Tobutt (2009) Development of "universal" gene-specific markers from Malus spp. cDNA sequences, their mapping and use in synteny studies within Rosaceae. Tree Genet. Genomes 5: 133-145.

Sawamura, Y., T. Saito, N. Takada, T. Yamamoto, T. Kimura, T. Hayashi and K. Kotobuki (2004) Identification of parentage of Japanese pear 'Housui'. J. Japan. Soc. Hort. Sci. 73: 511-518.
Shulaev, V., S.S. Korban, B. Sosinski, A.G.Abbott, H.S.Aldwinckle, K.M.Folta，A.Iezzoni，D.Main，P.Arús，A.M.Dandekar et al. (2008) Multiple models for Rosaceae genomics. Plant Physiol. 147: 985-1003.

Shulaev, V., D.J.Sargent, R.N. Crowhurst, T.C. Mockler, O. Folkerts, A.L.Delcher, P. Jaiswal, K. Mockaitis, A.Liston, S.P. Mane et al. (2011) The genome of woodland strawberry (Fragaria vesca). Nat. Genet. 43: 109-116.

Silfverberg-Dilworth,E., C.L.Matasci, W.E. Van de Weg, M.P.W. Van Kaauwen, M. Walser, L.P. Kodde, V. Soglio, L. Gianfranceschi, C.E. Durel, F. Costa et al. (2006) Microsatellite markers spanning the apple (Malus $\times$ domestica Borkh.) genome. Tree Genet. Genomes 2: 202-224.

Soriano, J.M., C.Romero, S.Vilanova, G.Llacer and M.L. Badenes (2005) Genetic diversity of loquat germplasm (Eriobotrya japonica (Thunb.) Lindl.) assessed by SSR markers. Genome 48: 108-114.

Sosinski,B., M.Gannavarapu， L.D.Hager， L.E.Beck， G.J.King, C.D. Ryder, S. Rajapakse, W.V. Baird, R.E. Ballard and A.G.Abbott (2000) Characterization of microsatellite markers in peach [Prunus persica (L.) Batsch]. Theor. Appl. Genet. 101: 421-428.

Staton, M., T.Zhebentyayeva, B.Olukolu, G.C.Fang, D. Nelson, J.E.Carlson and A.G.Abbott (2015) Substantial genome synteny preservation among woody angiosperm species: comparative genomics of Chinese chestnut (Castanea mollissima) and plant reference genomes. BMC Genomics 16: 744.

Struss, D., M. Boritzki, R. Karle and A.F. Iezzoni (2002) Microsatellite markers differentiate eight Giessen cherry rootstocks. HortScience 37: 191-193.

Terakami, S., M. Shoda, Y.Adachi, T. Gonai, M. Kasumi, Y. Sawamura, H. Iketani, K. Kotobuki, A. Patocchi, C. Gessler et al. (2006) Genetic mapping of the pear scab resistance gene Vnk of Japanese pear cultivar Kinchaku. Theor. Appl. Genet. 113: 743-752.

Terakami, S., Y.Adachi, H. Iketani, Y. Sato, Y. Sawamura, N.Takada, C. Nishitani and T. Yamamoto (2007) Genetic mapping of genes for susceptibility to black spot disease in Japanese pears. Genome 50: 735-741.

Terakami, S., T.Kimura, C.Nishitani, Y.Sawamura, T.Saito, T. Hirabayashi and T. Yamamoto (2009) Genetic linkage map of the Japanese pear 'Housui' identifying three homozygous genomic regions. J. Japan. Soc. Hort. Sci. 78: 417-424.

Terakami, S., C. Nishitani and T. Yamamoto (2013) Development of SNP markers for marker-assisted selection in pear. Acta Hortic 976: 463-469.

Terakami, S., C.Nishitani, M.Kunihisa, K. Shirasawa, S. Sato, S. Tabata, K.Kurita, H.Kanamori, Y.Katayose, N.Takada et al. (2014) Transcriptome-based single nucleotide polymorphism markers for genome mapping in Japanese pear (Pyrus pyrifolia Nakai). Tree Genet. Genomes 10: 853-863.

Testolin, R., T. Marrazzo, G. Cipriani, R. Quarta, I. Verde, M.T. Dettori, M. Pancaldi and S. Sansavini (2000) Microsatellite DNA in peach [Prunus persica (L.) Batsch] and its use in fingerprinting and testing the genetic origin of cultivars. Genome 43: 512-520.

van Dyk, M.M., M.K. Soeker, I.F. Labuschagne and D.J.G. Rees (2010) Identification of a major QTL for time of initial vegetative budbreak in apple (Malus $\times$ domestica Borkh.). Tree Genet. Genomes 6: 489-502.

Velasco, R., A.Zharkikh, J.Affourtit, A.Dhingra, A.Cestaro, A. Kalyanaraman, P.Fontana, S.K. Bhatnagar, M.Troggio, D. Pruss et al. (2010) The genome of the domesticated apple (Malus $\times$ domestica Borkh.). Nat. Genet. 42: 833-839.

Verde, I., N.Bassil, S. Scalabrin, B.Gilmore, C.T.Lawley, K. Gasic, 
D. Micheletti, U.R.Rosyara, F.Cattonaro, E.Vendramin et al. (2012) Development and evaluation of a 9K SNP array for peach by internationally coordinated SNP detection and validation in breeding germplasm. PLoS ONE 7: e35668.

Verde,I., A.G.Abbott, S. Scalabrin, S.Jung, S. Shu, F. Marroni, T. Zhebentyayeva, M.T.Dettori, J.Grimwood, F.Cattonaro et al. (2013) The high-quality draft genome of peach (Prunus persica) identifies unique patterns of genetic diversity, domestication and genome evolution. Nat. Genet. 45: 487-494.

Vilanova, S., D.J. Sargent, P.Arús and A. Monfort (2008) Synteny conservation between two distantly-related Rosaceae genomes: Prunus (the stone fruits) and Fragaria (the strawberry). BMC Plant Biol. 8: 67 .

Weber, J.L. and P.E. May (1989) Abundant class of human DNA polymorphisms which can be typed using the polymerase chain reaction. Am. J. Hum. Genet. 44: 388-396.

Wu, J., Z. Wang, Z. Shi, S.Zhang, R. Ming, S.Zhu, M.A. Khan, S. Tao, S.S. Korban, H. Wang et al. (2013) The genome of the pear (Pyrus bretschneideri Rehd.). Genome Res. 23: 396-408.

Wu,J., L.T.Li, M.Li, M.A.Khan, X.G.Li, H.Chen, H.Yin and S.L.Zhang (2014) High-density genetic linkage map construction and identification of fruit-related QTLs in pear using SNP and SSR markers. J. Exp. Bot. 65: 5771-5781.

Yamamoto, T., T. Kimura, Y. Sawamura, K. Kotobuki, Y. Ban, T. Hayashi and N. Matsuta (2001) SSRs isolated from apple can identify polymorphism and genetic diversity in pear. Theor. Appl. Genet. 102: 865-870.

Yamamoto, T., T. Kimura, M. Shoda, Y.Ban, T. Hayashi and N. Matsuta (2002a) Development of microsatellite markers in the Japanese pear (Pyrus pyrifolia Nakai). Mol. Ecol. Notes 2: 14-16.

Yamamoto, T., T.Kimura, Y.Sawamura, T.Manabe, K. Kotobuki, T. Hayashi, Y. Ban and N. Matsuta (2002b) Simple sequence repeats for genetic analysis in pear. Euphytica 124: 129-137.

Yamamoto, T., T.Kimura, M.Shoda, T.Imai, T. Saito, Y.Sawamura, K. Kotobuki, T. Hayashi and N. Matsuta (2002c) Genetic linkage maps constructed by using an interspecific cross between Japanese and European pears. Theor. Appl. Genet. 106: 9-18.
Yamamoto, T., K. Mochida, T. Imai, Y.Z. Shi, I. Ogihara and T. Hayashi (2002d) Microsatellite markers in peach (Prunus persica (L.) Batsch) derived from an enriched genomic and cDNA libraries. Mol. Ecol. Notes 2: 298-301.

Yamamoto, T., K. Mochida and T.Hayashi (2003) Shanhai Suimitsuto, one of the origins of Japanese peach cultivars. J. Japan. Soc. Hort. Sci. 72: 116-121.

Yamamoto, T., T.Kimura, T.Saito, K. Kotobuki, N. Matsuta, R. Liebhard, C.Gessler, W.E.van de Weg and T.Hayashi (2004a) Genetic linkage maps of Japanese and European pears aligned to the apple consensus map. Acta Hortic. 663: 51-56.

Yamamoto, T., T. Kimura, J. Soejima, T. Sanada, Y. Ban and T. Hayashi (2004b) Identification of quince varieties using SSR markers developed from pear and apple. Breed. Sci. 54: 239-244.

Yamamoto, T., M. Yamaguchi and T.Hayashi (2005) An integrated genetic linkage map of peach by SSR, STS, AFLP and RAPD. J. Japan. Soc. Hort. Sci. 74: 204-213.

Yamamoto, T., T.Kimura, S.Terakami, C.Nishitani, Y.Sawamura, T. Saito, K. Kotobuki and T.Hayashi (2007) Integrated reference genetic linkage maps of pear based on SSR and AFLP markers. Breed. Sci. 57: 321-329.

Yamamoto, T., S.Terakami, S. Moriya, F.Hosaka, K. Kurita, H. Kanamori, Y.Katayose, T.Saito and C.Nishitani (2013) DNA markers developed from genome sequencing analysis in Japanese pear (Pyrus pyrifolia). Acta Hortic. 976: 477-483.

Yamamoto, T., S.Terakami, N.Takada, S. Nishio, N.Onoue, C. Nishitani, M. Kunihisa, E. Inoue, H. Iwata, T. Hayashi et al. (2014) Identification of QTLs controlling harvest time and fruit skin color in Japanese pear (Pyrus pyrifolia Nakai). Breed. Sci. 64: 351-361.

Zhang, M.Y., L.Fan, Q.Z.Liu, Y. Song, S.W.Wei, S.L.Zhang and J. Wu (2014) A novel set of EST-derived SSR markers for pear and cross-species transferability in Rosaceae. Plant Mol. Biol. Rep. 32: 290-302.

Zhang, Q., W.Chen, L.Sun, F.Zhao, B.Huang, W.Yang, Y.Tao, J. Wang, Z. Yuan, G. Fan et al. (2012) The genome of Prunus mume. Nat. Commun. 3: 1318. 